\title{
The magician's forceps phenomenon in exotropia under general anaesthesia*
}

\author{
OSAMU TAMURA ${ }^{\prime}$ AND YUKIHIKO MITSUI ${ }^{2}$ \\ From the 'Department of Ophthalmology, Ehime University School of Medicine, and the \\ ${ }^{2}$ Department of Ophthalmology, Tokushima University School of Medicine, Japan
}

SUmmary Prifinium bromide was administered for eight weeks to three patients with exotropia. Under general anaesthesia active discharges from the lateral rectus muscles were demonstrated by electromyography. When a slight adductive force was applied to the straight or the master eye, active discharge from the lateral rectus of the associate eye disappeared in all patients, and this eye moved in the direction of orthophorisation. The discharge reappeared when the master eye was released from the forced adduction. From these results the authors concluded that proprioception is involved in the magician's forceps phenomenon discovered by Mitsui in exotropic patients in 1978.

The magician's forceps phenomenon is the orthophorisation of exotropia when a slight adductive force is applied to the straight, or master, eye. It was first reported by Mitsui in 1978.' This phenomenon is characterised by monocular movement of the slave eye in the direction of orthophorisation, as shown by electromyography. ${ }^{2}$ Once the phenomenon appears, it does not disappear when the master eye is covered, even in cases in which the slave eye has no sight,,$^{23}$ and the reflex responds to $9 \mathrm{~Hz}$ forced adduction. ${ }^{3}$ These facts suggested the involvement of proprioception in the phenomenon. However, the phenomenon does not appear during forced adduction, ${ }^{2}$ so that the importance of visual input has also been stressed. ${ }^{23}$. Therefore it was supposed that the development of the phenomenon ${ }^{3}$ was due to an interaction between the proprioceptive and visual afferents. This supposition was also suggested by the results of a series of basic studies on animals. ${ }^{s-7}$

Recently Tamura and Mitsui' studied the optomotor effect and the effect of retrobulbar anaesthesia in exotropic patients using electromyography after treatment with prifinium bromide, when there was active discharge from the lateral recti under general anaesthesia. The results strongly suggested that an interaction between the proprioceptive and visual

* Read in part before the 5th meeting of the International Neuroophthalmology Society, Antwerp, 14-18 May 1984.

Correspondence to Professor O Tamura, Department of Ophthalmology, Ehime University School of Medicine, Shigenobu, Ehime 791-02, Japan. afferents is involved in the firing from the lateral recti.

The present study was performed on exotropic patients treated with prifinium to determine whether or not forced adduction of the master eye causes the magician's forceps phenomenon under general anaesthesia, and thus to prove the presence of a stretch reflex in extraocular muscles.

\section{Materials and methods}

Three patients of constant exotropia, two males and a female ranging in age from 8 to 34 years, were given prifinium bromide for eight weeks in the manner reported previously. ${ }^{7}$ Electromyograms (EMGs) of the four horizontal rectus muscles were taken under general anaesthesia as in the method described earlier. ${ }^{8}$ In all three patients active discharges were emitted from both lateral recti, or at least from the lateral rectus of the slave eye. A slight adductive force was then applied to the straight, or master, eye by pulling a silk thread inserted at the medial limbus. The forced adduction was continued for two minutes. The experiment was done under the illumination with skialytic light.

All experiments were performed with the informed consent of the patients.

\section{Results}

The magician's forceps phenomenon, as revealed by EMGs, occurred in all the three patients examined 
Fig. 1 EMGs showing the magician's forceps phenomenon under general anaesthesia in a patient with exotropia of the left eye treated with prifinium. Discharge from the left (slave) lateral rectus tapers off when forced adduction is applied to the right (master) eye, and reappears when this eye is released from forced adduction.

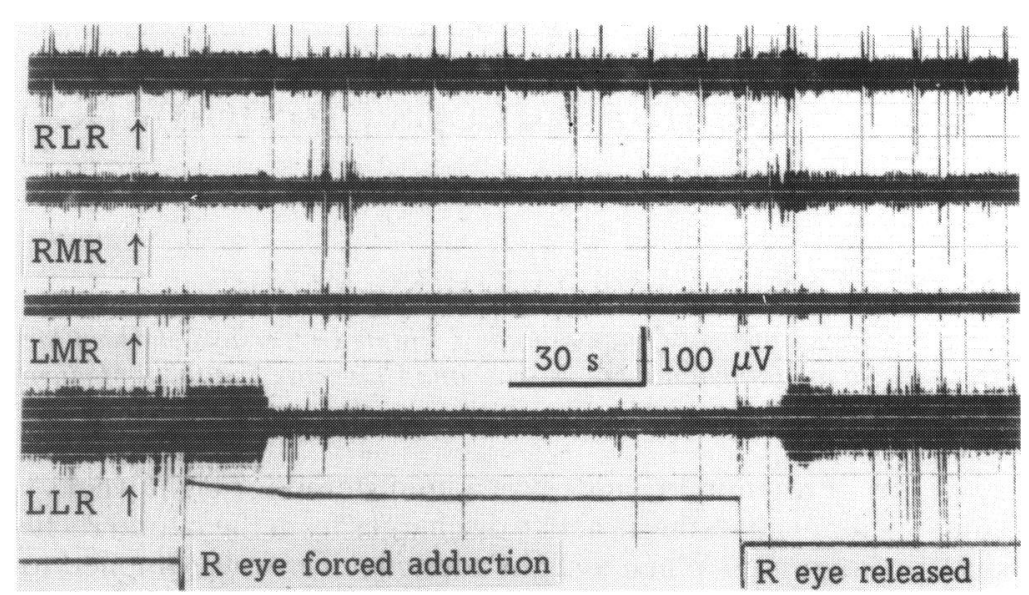

under general anaesthesia. Examples are shown in Figs. 1 and 2A, B.

Fig. 1 shows the EMGs obtained from a 23-yearold male suffering from constant exotropia of the left eye. The deviation was $28^{\circ}$, and vision was $20 / 20$ in both eyes. When prifinium bromide was administered orally for eight weeks, at a dosage of $15 \mathrm{mg}$ three times a day, the deviation became slightly greater. Under general anaesthesia the deviation was seen mostly in the left eye. The EMGs revealed a considerable amount of active discharge from the left lateral rectus. When a slight forced adduction was applied to the right, or master, eye, active discharge from the lateral rectus of the left, or slave, eye disappeared 16 to 19 seconds after application. The forced adduction was maintained for two minutes and then the right eye was released. Active discharge from the left lateral rectus reappeared about eight seconds after release of adduction. The horizontal recti of the right eye showed little change throughout.

Figs. 2A, B show EMGs obtained from a 15-yearold girl suffering from constant exotropia of the left eye. The deviation was $25^{\circ}$, and vision was $20 / 20$ in the right and 20/100 in the left eye with no organic changes (amblyopia). The deviation became slightly greater when prifinium bromide was administered at a dosage of $45 \mathrm{mg}$ a day for eight weeks. Under general anaesthesia both eyes showed a 'symmetrical exodeviation,' and active discharges were seen from both lateral recti (Fig. 2A). When a slight forced adduction was applied to the right (master) eye, active discharge from the left (slave) lateral rectus disappeared 24 to 34 seconds later. At the same time active discharge appeared from the medial rectus of the same eye. When the master eye was released from the forced adduction, active discharge from the slave medial rectus disappeared in 7 to 15 seconds accompanied by the reappearance of active discharge from the lateral rectus of the same eye in the course of 30 to 35 seconds, so that the EMGs returned to the original pattern. No obvious changes were seen in the EMGs of the right (master) eye muscles to which the forced adduction was applied.

When the same procedure was repeated twice, as shown in Fig. 2B, changes similar to those observed in the first attempt appeared in the EMG of the left lateral rectus but no changes appeared in the medial rectus.

In each case movement of the slave eye in the direction of orthophorisation appeared insidiously after a long time lag during forced adduction to the master eye.

\section{Discussion}

The present experiment showed that the magician's forceps phenomenon occurs under general anaesthesia. The indispensability of visual input for the transmission of proprioceptive afferents from ocular muscles had been suggested by a series of investigations..$^{2-79}$ The present experiment was therefore done in the light. Under general anaesthesia the slip of the retinal image has nothing to do with the ocular movement, so that the present result must be considered to be due to the stretch reflex transmitted through a subcortical pathway, most probably after an interaction with the visual afferent.

Ishikawa ${ }^{10}$ showed that in conscious patients the reverse phase reflex" can be brought about by forced duction of the excited eye by the use of a black suction contact lens, but there is a time lag of about seven seconds, and in addition the reflex appears only when the slave eye is also covered by a black contact lens.

It is not surprising, therefore, that in the experiment by Keller and Robinson ${ }^{12}$ the stretch reflex did 


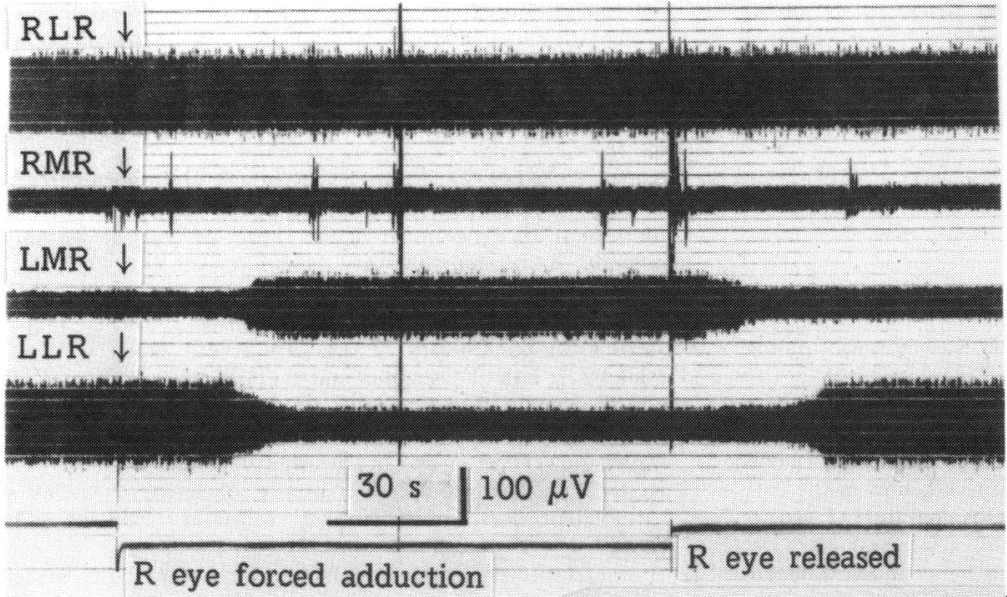

Fig. 2A
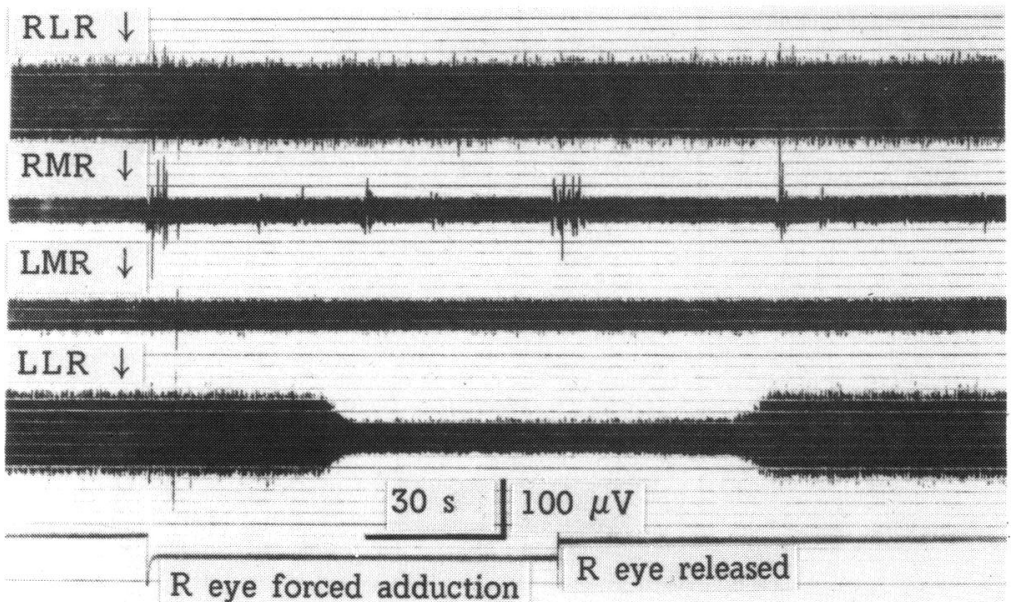

Fig. 2 EMGs showing the magician's forceps phenomenon under general anaesthesia in another patient with exotropia of the left eye treated with prifinium. A: By forced adduction of the right (master) eye, there is disappearance of discharge from the left (slave) lateral rectus accompanied by an increase of discharge from the medial rectus of the same eye, and EMGs return to the original pattern by release from forced adduction of the right eye. B: As above, but not accompanied by an increase in discharge from the medial rectus, obtained by repeated attempts in the same patient.

Fig. 2B

not appear in the EMG, because they covered the eye to which the forced duction was given while the associate eye was opened and the forced duction was given only $300 \mathrm{~ms}$. However, the experiments by Breinin ${ }^{13}$ and Maruo $^{14}$ showed a positive stretch reflex by EMG. Another reason for the negative result reported by Keller and Robinson may be due to the fact that they measured the reflex in the ipsilateral lateral rectus. Our series of studies have shown that the reflex is chiefly transmitted to the contralateral lateral rectus.

The magician's forceps phenomenon is a monocular movement of the slave eye in the direction of orthophorisation when studied by EMGs in conscious patients. ${ }^{2}$ This phenomenon in conscious patients is of two types. ${ }^{23}$ In one the slave eye assumes a position slightly off the straight position, and in the other the slave eye assumes the straight position, when a slight adductive force is applied to the master eye. In both types the EMGs show a tapering off of abnormal discharge from the lateral rectus of the slave eye accompanied by an increase in the discharge of the medial rectus. However, in the first type of response the EMGs of the medial and lateral rectus muscles are finely balanced, whereas in the second type dominance of the medial rectus appears. These two types are not person-specific, and either may appear in the same patient during repetition of the attempts. The present experiment showed that in the magician's forceps phenomenon under general anaesthesia equivalents to these two types can also appear in EMGs. The only difference is the length of the time lag under general anaesthesia.

The optomotor effect under general anaesthesia appears after long time lags. ${ }^{79}$ The stretch reflex shows the same delay under general anaesthesia. In 
addition, darkness and stretching show the same effect in the same pattern on the EMGs of exotropia. These facts may contribute to our further understanding of the mechanism of interaction between the visual and muscle afferents.

\section{References}

1 Mitsui Y. Etiology and treatment of strabismus. Ophthalmic Practice (Japan) 1978; 49: 1151-66.

2 Mitsui Y, Hirai K, Akazawa K, Masuda K. The sensorimotor reflex and strabismus. Jpn J Ophthalmol 1979; 23: 227-56.

3 Mitsui Y, Tamura O. Proprioception and exodeviations. $\mathrm{Br} \mathrm{J}$ Ophthalmol 1981; 65: 578-84.

4 Abrahans VC, Rose PK. Projections of extraocular, neck muscles, and retinal afferents to superior colliculus in the cat: their connections to cells of origin of tectospinal tract. J Neurophysiol 1975; 38: 10-8.

5 Donaldson IML, Long AC. Interactions between extra-ocular proprioceptive and visual signals in the superior colliculus of the cat. J Physiol (Lond) 1980; 298: 85-110.

6 Enomoto H, Matsumura M, Tsutsui J. Projections of extraocular muscle afferents to the visual cortex in the cat. Neuro-ophthalmology 1983; 3: 49-57.
7 Tamura O, Mitsui Y. Electromyographic study of the optomotor effect in exotropia under general anesthesia. Neuro-ophthalmology 1983; 4: 141-50.

8 Mitsui Y, Tamura O, Hirai K, Akazawa K, Ohga M, Masuda K. An electromyographic study of esotropia. Br J Ophthalmol 1981 65: $161-6$.

9 Mitsui Y, Tamura O, Berard PV, Reydy R. Optomotor effect in esotropia under general anesthesia. In: Reinecke RD, ed. Strabismus II. Proceedings of the Fourth Meeting of the International Strabismological Association, 25-29 Oct 1982. New York: Grune and Stratton, 1984: 429-38.

10 Ishikawa S. Problems related to amblyopia. 29th meeting of Japan Orthoptic Council. 27 May 1979, Kyoto, Japan.

11 Ishikawa S. Latent nystagmus and its etiology. In: Reinecke RD, ed. Strabismus, Proceedings of the Third Meeting of the International Strabismological Association, 10-12 May 1978, Kyoto, Japan. New York: Grune and Stratton, 1979: 203-14.

12 Keller EL, Robinson DA. Absence of a stretch reflex in extraocular muscles of the monkey. J Physiol (Lond) $1971 ; 34$ : 908-19.

13 Breinin GM. Electromyographic evidence for ocular muscle proprioception in man. Arch Ophthalmol 1957; 57: 176-80.

14 Maruo T. Electromyographical studies on stretch reflex in human extraocular muscle. Jpn J Ophthalmol 1964; 8: 97-111.

Accepted for publication 24 May 1985. 